\title{
Etiology of Allergic Contact Dermatitis based on Patch Test
}

\author{
Dita Maulida Anggraini, ${ }^{1}$ Endang Sutedja, ${ }^{2}$ Achadiyani $^{3}$ \\ ${ }^{1}$ Faculty of Medicine Universitas Padjadjaran, ${ }^{2}$ Department of Anatomical Pathology Faculty of \\ Medicine Universitas Padjadjaran/Dr. Hasan Sadikin General Hospital Bandung, ${ }^{3}$ Department \\ of Internal Medicine Faculty of Medicine, Universitas Padjadjaran/Dr. Hasan Sadikin General \\ Hospital Bandung
}

\begin{abstract}
Background: Allergic contact dermatitis is a type of contact dermatitis, whose prevalence tends to increase every year. Patch test is an important diagnostic test to confirm the disease. The result of patch test can help doctors to perform appropriate treatment. The aim of the study was to identify the most frequent allergen causing allergic contact dermatitis based on patch test results.

Methods: This was a descriptive retrospective study among patients who underwent patch test at the Dermatology and Venereology Clinic in Dr.Hasan Sadikin General Hospital Bandung, Indonesia from August 1st, 2014 to August 31st, 2015. The patch test result was obtained from the patient's medical record and recapitulation data. The patient's medical record would be collected based on inclusion and exclusion criteria. This study also collected demographic data of the patients, including age, sex, and occupation.The collected data were presented using tables.

Results: Out of 45 patient's medical records, 19 patients were male (42.2\%) and 26 patients were female $(57.8 \%)$. Nickel sulphate was the most frequent allergen with 17 sensitization. Thirteen out of 17 patients who were sensitized by nickel sulphate were females. A great majority of the patients were in the age group of 15-44 years. Most of the patients were students (42.2\%). Allergic contact dermatitis (64.4\%) was the main clinical diagnosis among the patients.
\end{abstract}

Conclusions: The most frequent allergen causes allergic contact dermatitis is nickel sulphate.

Keywords: Allergic contact dermatitis, nickel sulphate, patch test

\section{Introduction}

Allergic contact dermatitis (ACD) is an inflammatory process of the skin caused by a specific allergen. It is included in Type-IV Hypersensitivity, which the patient has been previously sensitized to the allergens. The North American Contact Dermatitis Group (NACDG) reports from 2009-2010 and 20112012 , indicated that the prevalence of ACD has increased from $46.3 \%$ to $48.0 \%{ }^{1,2}$ Prevalence of ACD patients treated at Dr. Mohammad Hoesin General Hospital Palembang, in 2008 reached $13.42 \%{ }^{3}$

Allergic contact dermatitis can be caused by several factors including genetic, age, gender, occupation, and other comorbidities such as irritant contact dermatitis (ICD), atopic dermatitis, and chronic urticaria. Clinical manifestations of ACD vary from erythematous macules, swelling, papulovesicles, to bullae or ulcer in severe cases. Pruritus is the main symptom found in ACD patients. ${ }^{4}$

Diagnosis of ACD can be performed by anamnesis and physical examination..$^{5}$ One of the tests used to confirm the diagnosis is the patch test. The test is carried out by attaching chamber/patch which has been given the substances to suspected patient's skin. ${ }^{6}$ Positive result of the test for at least one allergen confirm the diagnosis. Patch test results help doctors in patient education and therapy. In Indonesia, studies about the frequency of allergen sensitization have not been much carried out. The aim of the study was to identify the most frequent allergen causing ACD based on patch test results

\section{Methods}

This was a retrospective, descriptive study of all patients who underwent the patch test

Correspondence: Dita Maulida Anggraini, Faculty of Medicine, Universitas Padjadjaran, Jalan Raya Bandung-Sumedang Km.21, Jatinangor, Sumedang, Indonesia, Email: anggrainid17@gmail.com 
from August 1st, 2014 to August 31st, 2015 at Dr.Hasan Sadikin General Hospital Bandung. This study used patient's medical records and recapitulation data as study tools. Fortyfive medical records from patients who had done patch test in the period August 2014 to August 2015 were included based on inclusion criteria: (1) The diagnosis of ACD was confirmed (2) Positive result for at least one allergen. Patch test with an irritant result would be excluded from the samples. The standardized allergen series used at Dr. Hasan Sadikin General Hospital were supplied by the Department of Dermatology and Venereology, Faculty of Medicine, Universitas Gajah Mada. There were 2 versions of standardized allergen series used between 2014-2015: 18-allergens series and 22-allergens series, with the total of both series was 24 allergens. In addition to the patch test results, this study also assessed the clinical diagnosis.

The study was conducted at the Outpatient Clinic of Dr. Hasan Sadikin General Hospital Bandung from September to November 2015. The collected data would be processed using computer software and presented in tables. The Ethical clearance was approved by the Health Research Ethics Committee of Dr. Hasan Sadikin General Hospital Bandung.

\section{Results}

Clinical diagnosis and demographic data of the patients showed that most of the patients were female and aged between 15 and 44 years. The most frequent clinical diagnosis of the patients was ACD (71.1\%). The patient's occupation was mostly student (42.2\%); housewife and private employee were similar in frequency (Table 1).

Out of 45 patients tested, 33 patients $(73.3 \%)$ had at least one positive reaction, and 12 patients had $\geq 3$ positive reactions. The most frequent allergen was nickel sulphate $(19.3 \%)$, followed by potassium dichromate $(10.2 \%)$ and cobalt chloride $(9.1 \%)$. There was an additional allergen, balsam tiger, which was tested only on one patient due to the indication of the substance as causal allergen (Table 2).

\section{Discussions}

Allergic contact dermatitis (ACD) is one of the classifications of contact dermatitis. This disease is caused by a hapten complex that penetrates through the skin and sensitizes the body. Predisposing factors of ACD
Table 1 Distribution of Patient's Clinical Diagnosis and Demographic Data

\begin{tabular}{lc}
\hline Variables & $\mathbf{n}(\%)$ \\
\hline Gender & $19(42.2)$ \\
Male & $26(57.8)$ \\
Female & \\
Age (years-old) & $2(4.4)$ \\
$<15$ & $36(80.0)$ \\
$15-44$ & $1(2.2)$ \\
$45-64$ & $1(2.2)$ \\
$>65$ & $5(11.1)$ \\
Unknown & \\
Occupation & $19(42.2)$ \\
Student & $11(24.4)$ \\
Housewife & $11(24.4)$ \\
Private employee & $4(8.9)$ \\
Government employee & \\
Clinical Diagnosis & $32(71.1)$ \\
Allergic contact dermatitis & $2(4.4)$ \\
Irritant contact dermatitis & $3(6.7)$ \\
Atopic dermatitis & $3(6.7)$ \\
Chronic urticaria & $1(2.2)$ \\
Pemphigus vulgaris & $1(2.2)$ \\
Numular dermatitis & $1(2.2)$ \\
Erythema nodosum & $2(4.4)$ \\
Other &
\end{tabular}

include genetic, gender, ages, occupational, and environmental factors. ${ }^{7}$ However, the main factor which affected this disease to be occurred is the exposure to allergen itself. If patients had never been exposed to the allergen, the disease would not likely occur, even if they had a genetic factor. So, exposure to suspected allergen is also important to confirm the diagnosis.

An important diagnostic test to confirm allergic contact dermatitis is the patch test. This test is performed to differentiate whether it is an allergy or not. This test uses a set of standardized allergens series and attaches them by using a patch/chamber in the patient's skin. The diagnosis can be confirmed with only one positive result.

This study discovered that the greater predominance of patients with ACD was female. A study in a Brazilian population group ${ }^{8}$ and North American Contact Dermatitis Group 
Table 2 Frequency of Allergen Test

\begin{tabular}{|c|c|c|c|}
\hline Allergens Test & No. of patients tested & $\begin{array}{l}\text { Frequency of } \\
\text { Sensitization }\end{array}$ & $\begin{array}{c}\text { Percentage } \\
(\%)\end{array}$ \\
\hline Nickel sulphate $5 \%$ & 45 & 17 & 19.3 \\
\hline Balsam Peru 25\% & 45 & 4 & 4.6 \\
\hline Potassium dichromate $0,5 \%$ & 45 & 9 & 10.2 \\
\hline Cobalt chloride $1 \%$ & 45 & 8 & 9.1 \\
\hline Benzocaine 5\% & 45 & 1 & 1.1 \\
\hline Formaldehyde $1 \%$ & 45 & 2 & 2.3 \\
\hline Cinnamic aldehyde $1 \%$ & 36 & 2 & 2.3 \\
\hline Irgasan $2 \%$ & 9 & 0 & 0.0 \\
\hline PABA $10 \%$ & 45 & 7 & 7.9 \\
\hline Hidroquinone $1 \%$ & 45 & 7 & 7.9 \\
\hline Neomycin sulphate $20 \%$ & 45 & 3 & 3.4 \\
\hline Lanolin & 45 & 2 & 2.3 \\
\hline Vaselin & 45 & 3 & 3.4 \\
\hline Benzophenone 3\% & 45 & 5 & 5.7 \\
\hline Methyl paraben 5\% & 45 & 1 & 1.1 \\
\hline 5-chloro-7-iodo hydroxyquinolone & 45 & 2 & 2.3 \\
\hline 2-mercapto-benzothiazole $2 \%$ & 45 & 1 & 1.1 \\
\hline p-phenilenediamine $0,5 \%$ & 45 & 4 & 4.6 \\
\hline Colophony $20 \%$ & 36 & 4 & 11.1 \\
\hline Clioquinol 5\% & 9 & 0 & 0.0 \\
\hline Quaternium-15 1\% & 9 & 1 & 11.1 \\
\hline Tetramethylthiurandisulphate $1 \%$ & 9 & 1 & 11.1 \\
\hline Diclofenac sodium salt $1 \%$ & 9 & 0 & 0 \\
\hline Ethylenediamine 1\% & 9 & 3 & 33.3 \\
\hline Tiger Balm & 1 & 1 & 100.0 \\
\hline
\end{tabular}

(NACDG) 2 reported a similar result $(71.5 \%$ and $68.6 \%$ female patients respectively). This finding may be related to the high exposure of allergenic substances among females. Example of the objects, especially in females, included jewelry (e.g. necklaces, earrings, bracelets, etc.), fragrances, soap, hair dyes, cosmetics, etc.

The range of patient's age found in this study was 11-70 years, in which 5 patients had unknown age. Thirty-six patients $(80.0 \%)$ were from the 15-44 age group. Only 2 patients were found in $\geq 45$ age group. Furthermore, Thaha $^{3}$ reported that $94.1 \%$ of patients in his study are in the adult age group $(17-<60)$. However, this finding was inversely related to other studies. A study in Poland ${ }^{9}$ reported that $55 \%$ of people examined are over 40 years old. While Adiani and Muslimin ${ }^{10}$ in their study on the characteristics of allergic contact dermatitis reported that $58.6 \%$ of patients are in the $>30$ age group.

Moreover, the 15-44 age group is a productive age group. This group of people was exposed to many sources of allergen, especially from the occupational environment. They had more opportunities for sensitization in their occupation, such as factory workers (e.g. rubber, metals, textiles), health-care workers (e.g. alcohol, drugs, cleanser), and labourers (e.g. cement, ink, paint).

Regarding occupation, 19 patients were students (42.2\%), making them as the most frequent occupation in this study. This finding 
was different from other studies. As explained by Thaha ${ }^{3}$, most of the patients work as government employees (40.0\%) and only $15.3 \%$ of patients are students. A study in $\mathrm{Brazil}^{8}$ found that $22.3 \%$ of patients work in commerce. These differences might be related to Dr. Hasan Sadikin General Hospital Bandung as teaching hospital. In this hospital, many co-assisting medical students were tested as patients due to the indications found in anamnesis and physical examination. Thus, the result, showed a higher percentage of students. As explained before, most of the patients were in age group 15-44 years. Students might also contribute to higher percentage of this age group.

The majority of patients were diagnosed as allergic contact dermatitis (71.1\%). Diagnosis could be performed by anamnesis and physical examination. The history of exposure, allergy, family with similar sign and symptom, and occupation could be asked in anamnesis to identify the suspected allergen. In addition, physical examination would be focused on characteristics of the lesion (e.g. location, shape, size, colour, pruritic sign, etc.). If there were any indication to contact dermatitis, doctors can perform an additional test such as the patch test. This test helps to differentiate contact dermatitis caused by allergen and irritant. Besides, allergic contact dermatitis can also appear as a complication from other skin conditions e.g. atopic dermatitis, nummular dermatitis, chronic urticaria, pemphigus vulgaris, etc. This explained the other diagnoses found among the patients in this study.

In this study, the most frequent allergen found was nickel sulphate, followed by potassium dichromate and cobalt chloride. This was similar to the findings from other studies, although some differences were found in the second and third most frequent allergens. A study in Palembang ${ }^{3}$ reported that the 3 most frequent allergens were nickel sulphate, fragrance mix, and 4-phenylenediamine free base. Calamita et al. ${ }^{8}$ reported nickel sulphate, perfume mix, and thimerosal as the most frequent allergens. Moreover, the top 3 allergens in this study were metallic allergens. This is similar to the study of Bordel-Gómez et al. ${ }^{11}$, with 4 top allergens, nickel sulphate, palladium chloride, cobalt chloride, and potassium dichromate. Many metallic products contain 2 or more metallic substances and simultaneous exposure between them can produce co-reactions and aggravate the symptoms. ${ }^{12}$
Moreover, nickel sulphate is one of the most frequent allergens in the world. Many reports have ranked this allergen as the top one. The North American Contact Dermatitis Group2 in 2011-2012 also reported nickel sulphate as the most frequent allergen. This finding was similar to NACDG report in 2009-2010. ${ }^{1}$ Many nickel-containing objects are strong sensitizer and soluble in water and sweat. ${ }^{4}$ Contact with the skin, nickel which has been corroded by water or sweat could trigger sensitization. Sources for this allergen included jewelry, buttons, watches, coins, etc.

Out of 17 patients who were sensitized by nickel sulphate, 13 patients were female (76.5\%). This also made nickel sulphate as the most common allergen among females. This finding might be related to the high exposure of nickel-containing objects among females. Example of the objects, especially in females, included jewelry (e.g. necklaces, earrings, bracelets, etc.), fragrances, soap, hair dyes, cosmetics, cooking pan, etc. Sources of allergen could be identified also from the pattern of lesion. For example, if the pattern was a thin and long lesion around the neck, the source of allergen is most likely a necklace.

As for male patients, potassium dichromate becomes the most frequent allergen with 6 sensitizations. Bordel-Gómez et al. ${ }^{11}$ also reported this allergen as the most common one among males. The sources of allergen are mostly from cement, tattoos, and leather material. ${ }^{12}$

The difference in standardized allergen series used from August 2014-August 2015 was the major limitation in this study. There were 2 versions of series: 18-allergen series and 22-allergen series. The latter one was used in the 2015 period. Cinnamic aldehyde and colophony were not included in this series. New allergens in this series were irgasan, clioquinol, Quaternium-15, tetramethylthiuran disulphate, ethylenediamine, and Tiger Balm (only tested in 1 patient). These differences could cause a decrease in the true frequency of those allergens. Furthermore, this study could not sum up the total frequency of sensitization and the percentage would not be exactly in onehundred percent. Other limitations are toosmall sample size and incomplete recording process in the patient's medical record.

As the conclusion, the most frequent allergen causing ACD based on patch test results is nickel sulphate, which is mostly found in females. Allergic contact dermatitis is the most frequent clinical diagnosis among the patients. The great majority of the patients are 
included in the age group of 15-44 years with student as their major occupation.

\section{References}

1. Warshaw EM, Belsito DV, Taylor JS, Sasseville D, DeKoven JG, Zirwas MJ, et al. North American Contact Dermatitis Group patch test results: 2009 to 2010. Dermatitis. 2013;24(2):50-9.

2. Warshaw EM, Maibach HI, Taylor JS, Sasseville D, DeKoven JG, Zirwas MJ, et al. North American Contact Dermatitis Group patch test results: 2011-2012. Dermatitis. 2015;26(1):49-59.

3. Thaha MA. Uji tempel dengan Finn dan Iq Chambers pada pasien dermatitis kontak alergi di Rumah Sakit Umum Pusat Dr. Mohammad Hoesin Palembang. Majalah Kedokteran Sriwijaya. 2014;46(2):11823.

4. Beck MH, Wilkinson SM. Contact dermatitis: allergic. In: Burns T, Breathnach S, Cox N, Griffiths C. Rook's textbook of dermatology. 8th ed. Oxford: Blackwell Publishing; 2010. p. 26.1-26.106.

5. Sasseville D. Occupational contact dermatitis. Allergy Asthma Clin Immunol. 2008;4(2):59-65.
6. Lazzarini R, Duarte I, Ferreira A. Patch tests. An Bras Dermatol. 2013;88(6):87988.

7. Peiser M, Tralau T, Heidler J, Api A, Arts J, Basketter D, et al. Allergic contact dermatitis: epidemiology, molecular mechanisms, in vitro methods and regulatory aspects. Cell Mol Life Sci. 2012;69(5):763-81.

8. Calamita Z, Alonso ACR, da Costa LCO, Calamita ABP. Main allergens observed in patients with contact dermatitis in a Brazilian population group. Open Dermatol J. 2015;9(5):21-4.

9. Reduta T, Bacharewicz J, Pawłoś A. Patch test results in patients with allergic contact dermatitis in the Podlasie region. Postepy Dermatol Alergol. 2013;30(6):350-7.

10. Adiani AD, Muslimin M. Karakteristik Dermatitis Kontak Alergi (DKA) di RSUP Dr. Kariadi. Media Medika Muda. 2014;3(1):1-25

11. Bordel-Gómez MT, Miranda-Romero A, Castrodeza-Sanz J. Epidemiology of Contact Dermatitis: Prevalence of Sensitization to Different Allergens and Associated Factors. Actas Dermosifiliogr. 2010;101(1):59-75.

12. Rietschel R, Fowler J, Fisher A. Fisher's Contact Dermatitis. 6th ed. Hamilton: BC Decker Inc; 2008. p. 653-60. 